\title{
Magnetic-supported cucurbituril: A recyclable adsorbent for the removal of humic acid from simulated water
}

\author{
QIN YANG*, YING JIANG, XIAOLI LI, YONGLI YANG and LIYUN HU \\ Department of Chemistry, School of Science, Xi'an University of Architecture and Technology, \\ Xi'an 710055, China
}

MS received 19 May 2013; revised 4 July 2013

\begin{abstract}
Magnetic cucurbituril (MQ[n]), a new functional material compound, was prepared via chemical co-precipitation method as a high-capacity adsorbent for humic acid (HA). The material was characterized by $X$-ray diffraction (XRD), scanning electron microscopy (SEM), Fourier transform infrared spectroscopy (FT-IR) and thermal gravimetric analysis (TGA), respectively, indicating that $Q[n]$ has been grafted on the surface of $\mathrm{Fe}_{3} \mathrm{O}_{4}$. Its adsorption-desorption behaviour towards $\mathrm{HA}$ from aqueous solution have been investigated. MQ[n] demonstrated good adsorption capacity at pH 7 in adsorption experiments. Adsorption isotherm could be well interpreted by the Freundlich isotherm model. Adsorption kinetic followed pseudosecond-order kinetics, which indicated that the limit factor of adsorption HA was adsorption mechanism. The negative value of thermodynamic parameters showed that adsorption process was spontaneous and exothermic. Moreover, the capacity of MQ[n] was also above $80 \%$ after being used for four times, so it may have potential industrial applications.
\end{abstract}

Keywords. Cucurbituril; magnetic; adsorption; humic acid; kinetics.

\section{Introduction}

Humic acid (HA), a mixture of stable, weak and alkaline natural polymers that resides as a predominant type of organics in natural waters (Baker and Khalili 2004), can react with chloric disinfectant of drinking water to produce by-products such as trihalomethane and haloacetic acids, which are known to be carcinogenic, teratogenic and mutagenic to human health. In the mean time, it can form complexes with heavy metals and pesticides, enhancing the material durability and biological accumulation (Domany et al 2002). Therefore, it is necessary to remove HA from wastewater. At present, a variety of methods including ultrafiltration, coagulation, biodegradation, ozonation and adsorption have been applied for removal of HA from wastewater (Latifoglu and Gurol 2003; Seredynska-Sobecka 2006; Senem et al 2007; Tang et al 2007; Ji et al 2008). Among them, adsorption has been paid close attention since it is simple, environmentally friendly and cost-effective (Koparal et al 2008). The commonly used adsorbents are activated carbon (Deng and Bai 2004), fly ash (Wang and Zhu 2007), chitosan (Anirudhan et al 2008), resin (Zhao et al 2008), polypropylene fiber membrane (Wang et al 2010) and polypyrrole (Bai and Zhang 2001).

*Author for correspondence (yangjiaxin929@163.com)
Cucurbituril $(\mathrm{Q}[n])$, a family of macrocyclic host molecules, possessing its unique structure of centre hydrophobic cavity and hydrophilic portals that can form stable clathrate compounds with guest molecules through van der Waals interaction (Peerannawar et al 2012), hydrophobic interaction (Feng et al 2009), electrostatic interaction (Buschmann et al 2000), hydrogen bonding (Karcher et al 2001a), ion-dipole (Buschmann et al 2006) or dipole-dipole interaction (Wei et al 2005; Zhang et al 2008). Q[5-8] are of the same height (9.1 $\AA)$; however, they all differ in the diameter of their carbonyl portals and cavities, which are 2.4-6.9 $\AA$ and 4.4-8.8 $\AA$, respectively (Petrov et al 2009; Saleh et al 2011). In addition, $\mathrm{Q}[n]$ is practically insoluble in all common organic solvents. The solubility in water given in the literature varies between 13 and $20 \mathrm{mmol} \mathrm{L}^{-1}$ (Karcher et al 2001a). Q $[n]$ has other advantages such as its strong rigid structure, stable chemical property and low toxicity (Wheate 2008). Therefore, $\mathrm{Q}[n]$ is considered as a promising functional material compounds with extensive applications in various fields, such as biomedicine, materials science, pharmacology and water treatment. Buschmann and Schollmeye (1993) found that Q[6] has high selectivity and capture ability for many ions, such as $\mathrm{Cr}$ and $\mathrm{Cu}$ in dye wastewater under the condition of high acidity. Therefore, it can be used in wastewater treatment. However, Lim et al (2008) applied Q[6] to water treatment and found that $\mathrm{Q}[6]$ can load more than $1 \mathrm{~g} \cdot \mathrm{g}^{-1}$ in 
appropriate conditions, but if the concentration and acidity of metal ions in the solution are too high, Q[6] will be dissolved and the amount of adsorption decreased. Furthermore, $\mathrm{Q}[n]$ was used as adsorbent to remove the reactive dye of printing and dyeing wastewater by Karcher et al (1999, 2001b) and exhibited high adsorption efficiency. But in the authentic printing and dyeing wastewater treatment, $\mathrm{Q}[n]$ was dissolved at least $20 \%$ and even cucurbituril precipitated on silica was partly dissolved, thus, inappropriate for printing and dyeing wastewater treatment. In addition, German scientists, Karcher et al (2001b), utilized chemical ozonation to dispose $\mathrm{Q}[n]$, which has adsorbed other molecules, but unfortunately, dissolved $\mathrm{Q}[n]$ was oxidated by ozone; thus, producing nitrite, nitrate, formic acid salt, acetate and oxalic acid salt, so that chemical oxygen demand (COD) content was too high to treat water in the recovery process. Our team has found good removal efficiency of HA adsorbed by $\mathrm{Q}[n]$, but we also encountered the problems mentioned earlier (Yang et al 2012). Therefore, it is important to seek a suitable support material applying to wastewater treatment system without losing the relevant properties.

Recently, magnetic carrier methods have been widely used in the processes of the separation of biological cells, coal desulphurization and the treatment of wastewater due to their magnetic properties, chemical stability, low toxicity and adsorption capacity, ease in synthesis and excellent recycling capability (Parsonage 1992). Not only does $\mathrm{MQ}[n]$ have stable structure and higher adsorption capacity, but also it is easily separated from wastewater. In this work, $\mathrm{MQ}[n]$ were prepared by chemical coprecipitation method and its morphology and structure was characterized. Adsorption and desorption behaviours of this interesting composite material were studied for HA in simulated water.

\section{Experimental}

\section{$2.1 \quad$ Materials}

Cucurbituril $(\mathrm{Q}[n])$ was prepared and purified following traditional method (Bardelang et al 2007). Ferrous ammonium sulfate hexahydrate $\left(\left(\mathrm{NH}_{4}\right)_{2} \mathrm{Fe}\left(\mathrm{SO}_{4}\right)_{2} \cdot 6 \mathrm{H}_{2} \mathrm{O}\right)$, ammonium ferric sulfate dodecahydrate $\left(\left(\mathrm{NH}_{4}\right) \mathrm{Fe}\left(\mathrm{SO}_{4}\right)_{3}\right.$. $12 \mathrm{H}_{2} \mathrm{O}$ ), ammonia, anhydrous ethanol were purchased from Kemiou Chemical Agent Company (TianJin, China). Humic acid (HA) was supplied by JvFen Chemical Agent Company (ShangHai, China). All other reagents used in this study were analytical grade.

\subsection{Preparation of $M Q[n]$}

As much as $1.5 \mathrm{~g}$ of $\mathrm{Q}[n], 1.7 \mathrm{~g}$ of $\left(\mathrm{NH}_{4}\right)_{2} \mathrm{Fe}\left(\mathrm{SO}_{4}\right)_{2} \cdot 6 \mathrm{H}_{2} \mathrm{O}$ and $2.51 \mathrm{~g}$ of $\left(\mathrm{NH}_{4}\right) \mathrm{Fe}\left(\mathrm{SO}_{4}\right)_{3} \cdot 12 \mathrm{H}_{2} \mathrm{O}$ were dissolved in $200 \mathrm{~mL}$ of deionized water. The suspension was sonicated for $10 \mathrm{~min}$. A total of $10 \mathrm{~mL}$ of $8 \mathrm{~mol} \mathrm{~L}^{-1} \mathrm{NH}_{3} \cdot \mathrm{H}_{2} \mathrm{O}$ was added dropwise after the solution was heated to $50{ }^{\circ} \mathrm{C}$ with vigorous stirring at a speed of $1000 \mathrm{rpm}$ in the presence of nitrogen. The $\mathrm{pH}$ was maintained at 11-12 during the whole reaction. After finishing the reaction, the precipitate was isolated from suspension by magnets, washed three times with anhydrous ethanol and deionized water, and dried in a vacuum oven at $60{ }^{\circ} \mathrm{C}$.

\subsection{Characterization}

The X-ray powder diffraction (XRD) pattern was recorded by an X-ray diffractometer (Bruker, German) using $\mathrm{CuK} \alpha$ radiation. The size and morphology of the samples were observed by scanning electron microscopy (S-570, Japan Hitachi). FT-IR measurements were performed by Fourier transform infrared spectrophotometer (Shimadzu IR-21, Japan) using $\mathrm{KBr}$ background in the range of 400$4000 \mathrm{~cm}^{-1}$. Thermal gravimetric analysis was conducted with METTLER TGA/DSC 1 STAR System thermal analyzer (Switzerland) at a heating rate of $10{ }^{\circ} \mathrm{C} \mathrm{min}^{-1}$ in a nitrogen atmosphere.

\subsection{Adsorption/desorption studies}

The effect of $\mathrm{pH}$ on the HA removal by $\mathrm{MQ}[n]$ was conducted by adding $0.02 \mathrm{~g}$ of $\mathrm{MQ}[n]$ to $20 \mathrm{~mL}$ of HA solution $\left(10 \mathrm{mg} \mathrm{L}^{-1}\right)$. The initial $\mathrm{pH}$ of $\mathrm{HA}$ solution was adjusted by $0.1 \mathrm{~mol} \mathrm{~L}^{-1} \mathrm{HCI}$ and $\mathrm{NaOH}$ ranging from 2 to 14 . After $12 \mathrm{~h}$, the liquid supernatant was measured at the maximum wavelength $(254 \mathrm{~nm})$ by $\mathrm{UV}-\mathrm{V}$ is spectrophotometer (Thermo, USA).

Adsorption experiments were carried out in a set of beakers containing $20 \mathrm{~mL}$ of HA solution at different concentrations ranging from 2 to $15 \mathrm{mg} \mathrm{L}^{-1}$. To each beaker, $\mathrm{pH}$ was adjusted to $7,0.02 \mathrm{~g} \mathrm{MQ}[n]$ was added and temperature was maintained at 25,35 and $45^{\circ} \mathrm{C}$ for $12 \mathrm{~h}$. The concentration of the residual HA was measured by UV-Vis spectrophotometer. The amount of HA adsorbed on MQ $[n]$ was calculated by the following equation (Samiey and Toosi 2010)

$$
Q_{\mathrm{e}}=\left(C_{0}-C_{\mathrm{e}}\right) V / M,
$$

where $Q_{\mathrm{e}}$ is the amount of adsorbed HA on a unit mass of $\mathrm{MQ}[n]\left(\mathrm{mg} \mathrm{g}^{-1}\right) ; C_{0}$ and $C_{\mathrm{e}}$ are the initial concentration and equilibrium concentration of $\mathrm{HA}$, respectively ( $\mathrm{mg}$ $\left.\mathrm{L}^{-1}\right) ; V$ the volume of HA solution (L) and $M$ the mass of $\mathrm{MQ}[\mathrm{n}](\mathrm{g})$. The standard curve of HA is $Y=-0.00107+$ $0.03642 \times X, R^{2}=0.9996$.

For the kinetic experiment, $0.02 \mathrm{~g}$ of $\mathrm{MQ}[n]$ was added into different concentrations of the HA solution at $25^{\circ} \mathrm{C}$. The $\mathrm{pH}$ was adjusted to 7 . At different time intervals, the remaining amount of HA in supernatant was determined using UV-Vis spectrophotometer. The adsorption amount was calculated according to (1). 
Desorption experiments were conducted by adding $0.02 \mathrm{~g}$ of MQ[n] to $20 \mathrm{~mL}$ of $\left(10 \mathrm{mg} \mathrm{L}^{-1}\right) \mathrm{HA}$ solution at $\mathrm{pH} 7$ for $12 \mathrm{~h}$. Aqueous samples were collected for further analysis. The MQ $[n]$ was separated from the solution using magnets and washed with $2 \mathrm{~mol} \mathrm{~L}^{-1} \mathrm{NaOH}$ and deionized water until the $\mathrm{pH}$ was 7 . Subsequently, the $\mathrm{MQ}[n]$ was used to remove the same concentration of HA solution again. The process was repeated four times.

\section{Results and discussion}

\subsection{Characterization of $M Q[n]$}

Figure 1 shows the XRD patterns of $\mathrm{Q}[n]$ and $\mathrm{MQ}[n]$. For the XRD patterns of Q $[n]$, there is a small hump $(2 \theta=23)$ corresponding to amorphous $\mathrm{Q}[n]$. However, all the characteristic peaks $(2 \theta=18 \cdot 3,30 \cdot 1,35 \cdot 5,37 \cdot 0,43 \cdot 2,53 \cdot 6$, $57 \cdot 0,62.7$ and $\left.74.1^{\circ}\right)$ at the XRD patterns of MQ[n] relate to their corresponding indices (111), (220), (311), (222), (400), (422), (511), (440) and (533), respectively. This indicates that $\mathrm{MQ}[n]$ is pure $\mathrm{Fe}_{3} \mathrm{O}_{4}$ with a spinal structure and it does not result in the phase change of $\mathrm{Fe}_{3} \mathrm{O}_{4}$. In addition, a small hump $(2 \theta=23)$ in the XRD pattern of $\mathrm{MQ}[n]$ suggests the existence of amorphous $\mathrm{Q}[n]$ on the $\mathrm{MQ}[n]$.

The SEM images of $\mathrm{Fe}_{3} \mathrm{O}_{4}$ and $\mathrm{MQ}[n]$ are shown in figure 2. Comparing two pictures, the surface of $\mathrm{Fe}_{3} \mathrm{O}_{4}$ cube is smooth and disperse, but after combination with the $\mathrm{Q}[n], \mathrm{Fe}_{3} \mathrm{O}_{4}$ cubes are loaded on the surface of cagelike $\mathrm{Q}[n]$ with high density.

FT-IR is one of the most useful tools to identify the structure of compounds. The FT-IR spectra of the Q $[n]$ and $\mathrm{MQ}[n]$ are shown in figure 3, revealing the bonding of MQ $[n]$ on the surface of magnetic particles. For the IR spectrum of $\mathrm{Q}[n]$, the strong peak located at $3443 \mathrm{~cm}^{-1}$ is

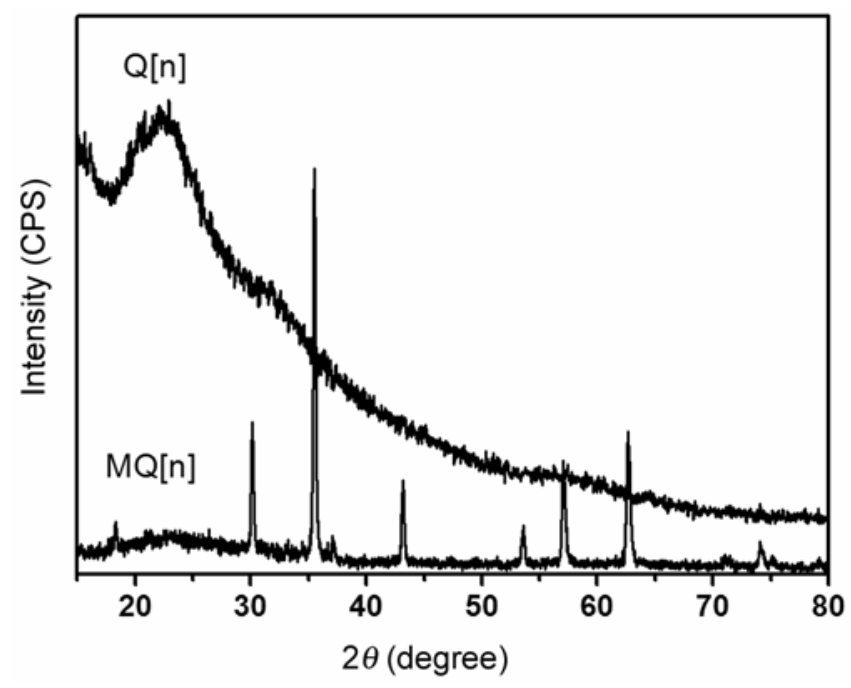

Figure 1. XRD patterns for $\mathrm{Q}[n]$ and $\mathrm{MQ}[n]$. crystal water of MQ[n], while peaks at 2930 and $1474 \mathrm{~cm}^{-1}$ correspond to $-\mathrm{CH}_{2}$ stretching vibration and bending vibration, respectively. The characteristic absorbance band around $1722 \mathrm{~cm}^{-1}$ relates to the $-\mathrm{C}=\mathrm{O}$ group. However, compared with the spectrum of $\mathrm{MQ}[n]$, it is notable that a new peak at $581 \mathrm{~cm}^{-1}$ appeared, which can be assigned to the $\mathrm{Fe}-\mathrm{O}$ group. Besides, the peaks of $-\mathrm{C}=\mathrm{O}$ group at $1722 \mathrm{~cm}^{-1}$ and $-\mathrm{CH}_{2}$ stretching and bending vibrations at 2930 and $1474 \mathrm{~cm}^{-1}$, which are slightly shifted to 1727, 2934 and $1478 \mathrm{~cm}^{-1}$, respectively. And another peak appearing at $1631 \mathrm{~cm}^{-1}$ indicates that there is a weak interaction between $-\mathrm{C}=\mathrm{O}$ group of $\mathrm{Q}[n]$ and $\mathrm{Fe}_{3} \mathrm{O}_{4}$, which means the generation of hydrogen bonds. The aformentioned lines of evidence indicate that $\mathrm{Q}[n]$ has been grafted successfully onto the surface of $\mathrm{Fe}_{3} \mathrm{O}_{4}$.

In order to confirm the grafting of $\mathrm{Q}[n]$ molecules onto $\mathrm{Fe}_{3} \mathrm{O}_{4}$, it is necessary to analyse the weight loss of the $\mathrm{MQ}[n]$. As shown in figure 4, it is observed that the weight loss process can be divided into three stages during the range of temperature. The first weight loss of $11.40 \%$ below $200{ }^{\circ} \mathrm{C}$ was due to water loss adhering to the sample. The second stage occurs from $300^{\circ} \mathrm{C}$ to about $600{ }^{\circ} \mathrm{C}$, which is related to the degradation of $\mathrm{Q}[n]$. This is a major weight loss of about $34.05 \%$ over the full temperature range. In addition, an unexpected weight loss of $19.05 \%$ appears by the end of the second stage to $800{ }^{\circ} \mathrm{C}$, which can be characterized by the oxidation of $\mathrm{Fe}_{3} \mathrm{O}_{4}$ to $\mathrm{Fe}_{2} \mathrm{O}_{3}$. This weight loss is consistent with the amount of $\mathrm{FeO}$ in $\mathrm{Fe}_{3} \mathrm{O}_{4}$. Compared with the loss of organic matter of about $34.05 \%$ and the residual amount of inorganic matter about $54.55 \%$, the composition of $\mathrm{Q}[n]: \mathrm{Fe}_{3} \mathrm{O}_{4}$ in the product is $\sim 1: 1 \cdot 5$. Moreover, $\mathrm{Q}[n]$ had been modified on the surface of $\mathrm{Fe}_{3} \mathrm{O}_{4}$, which could be demonstrated by XRD and FT-IR. Therefore, the proposed structural model of $\mathrm{MQ}[n]$ is shown in figure 5 .

\subsection{Adsorption of HA onto MQ[n]}

3.2a Effect of $p H$ : The $\mathrm{pH}$ of aqueous solution has a great influence on the HA adsorption onto $\mathrm{MQ}[n]$ and the results are illustrated in figure 6. Maximum uptake value for $\mathrm{HA}$ was obtained at $\mathrm{pH} 7$, which was selected as optimum $\mathrm{pH}$ for the other experiment. HA adsorption increased with the increase of $\mathrm{pH}$ from 2 to 7 , then dropped as $\mathrm{pH}$ continued to rise beyond 7. The results of the Vreysen and Maes (2008) research showed that the point of zero charge for the HA was 1.9. Therefore, the surface charge of the HA is negatively charged at the experimental conditions. However, nitrogen and carbonyl oxygen atoms on $\mathrm{Q}[n]$ are protonated at lower $\mathrm{pH}$, which are favourable to adsorption. At $\mathrm{pH}$ above 7, less nitrogen and carbonyl oxygen atoms are protonated and more deprotonated carbonyl group could compete with negatively charged HA, thus the adsorption capacity for the HA decreases. 

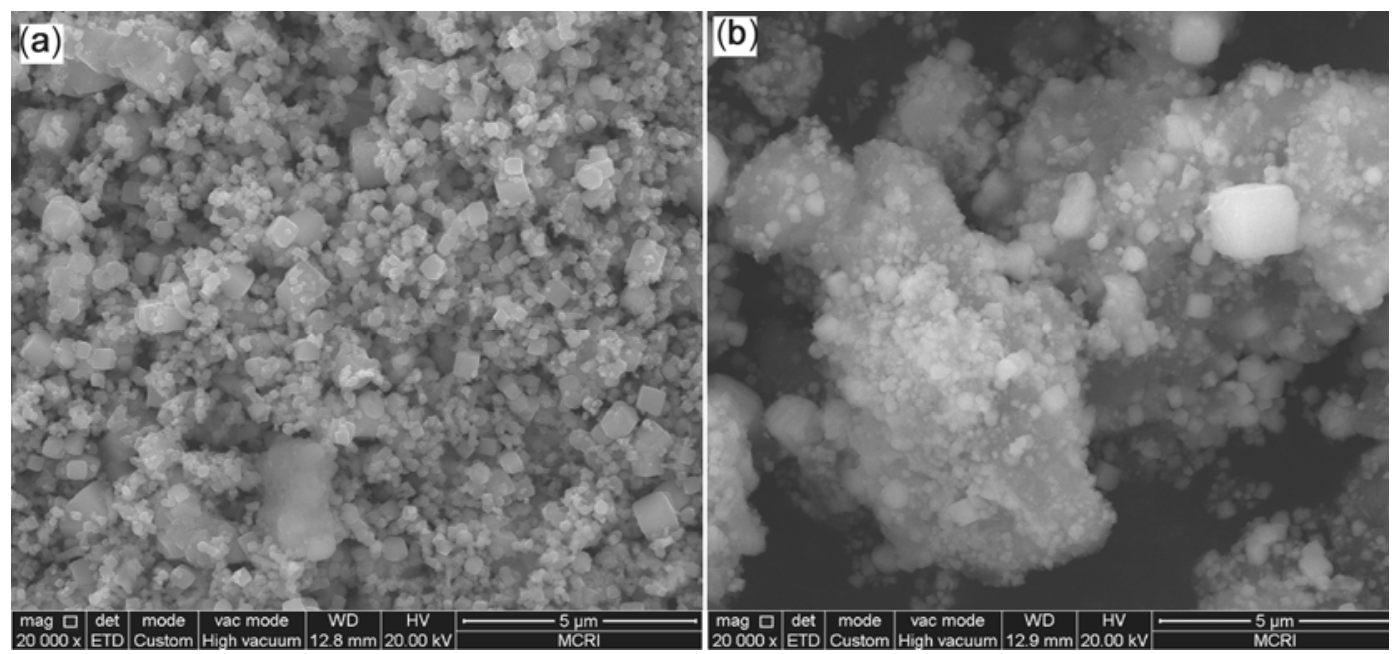

Figure 2. SEM images of $\mathrm{Fe}_{3} \mathrm{O}_{4}(\mathbf{a})$ and $\mathrm{MQ}[n](\mathbf{b})$.

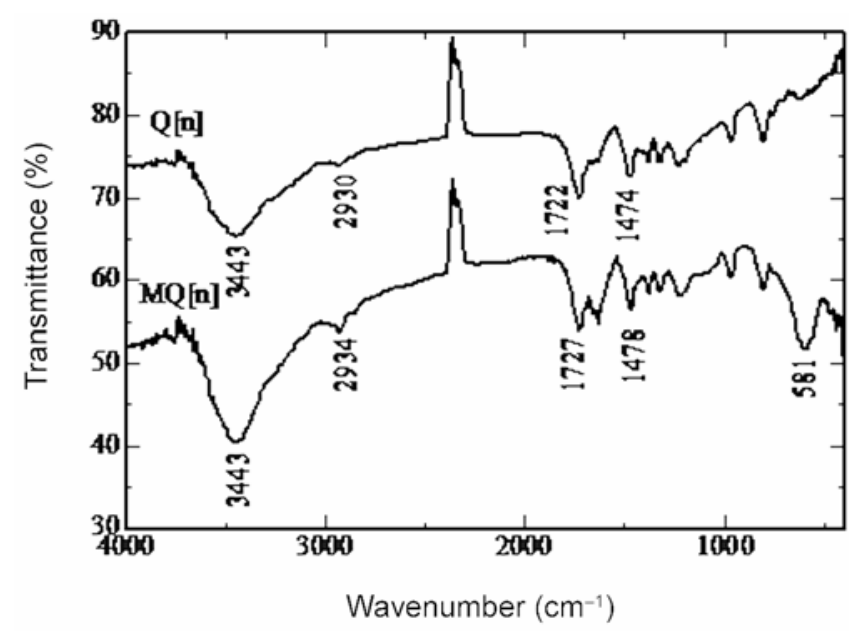

Figure 3. FT-IR spectra of $\mathrm{Q}[n]$ and $\mathrm{MQ}[n]$.

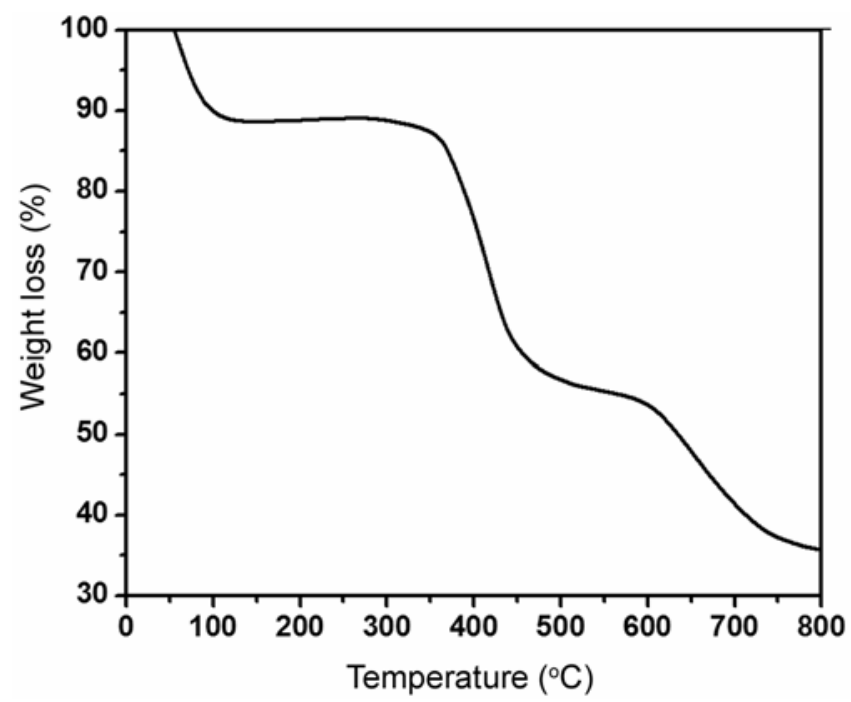

Figure 4. TGA curve of MQ[n]. 3.2b Adsorption isotherms: Figure 7 displays the adsorption isotherm of HA adsorption on MQ[n] at 298, 308 and $318 \mathrm{~K}$, respectively. The adsorption curves indicate that the equilibrium adsorption capacity of HA increases with the increase in HA concentration, but decreases with increasing temperature. In order to investigate the process of HA adsorption onto $\mathrm{MQ}[n]$, classical Langmuir isothermal adsorption theory and Freundlich equation are used, respectively, to study the adsorption mechanism (Langumuir 1918; Bayramoglu et al 2002).

Langmuir isothermal equation:

$$
C_{\mathrm{e}} / Q_{\mathrm{e}}=C_{\mathrm{e}} / Q_{\mathrm{m}}+1 /\left(Q_{\mathrm{m}} \cdot K_{\mathrm{L}}\right) \text {. }
$$

Freundlich isothermal equation:

$$
\ln Q_{\mathrm{e}}=\ln K_{\mathrm{F}}+1 / n \cdot \ln C_{\mathrm{e}},
$$

where $C_{\mathrm{e}}$ is the equilibrium concentration of $\mathrm{HA}$; $Q_{\mathrm{e}}$ the amount of adsorbed HA on a unit mass of MQ[n] $\left(\mathrm{mg} \mathrm{g}^{-1}\right)$; $Q_{\mathrm{m}}$ the maximum adsorption $\left(\mathrm{mg} \mathrm{g}^{-1}\right) ; K_{\mathrm{L}}$ the Langmuir binding constant $\left(\mathrm{L} \mathrm{mg}^{-1}\right)$, reflecting the energy of adsorption. $K_{\mathrm{F}}$ and $1 / n$ are the Freundlich constants $\left(\mathrm{mg} \mathrm{g}^{-1}\right)$ representing the adsorption capacity and intensity, respectively. The related parameters of Langmuir and Freundlich isotherms for HA adsorption are depicted in table 1 . The maximum adsorption at 298, 308 and $318 \mathrm{~K}$ was calculated using Langmuir adsorption isothermal model to be $29.38,19.10$ and $14.69 \mathrm{mg} \mathrm{g}^{-1}$, respectively, exhibiting high adsorption capacity of $\mathrm{MQ}[n]$. However, it was significantly different from maximum adsorption obtained by linear fitting and experiment. However, the Langmuir isotherm does not fit well. $1 / n$ is the isotherm constant of Freundlich adsorption isothermal model that is related to the adsorption intensity. It is acknowledged that adsorption is ideal when $0.1<1 / n<0.5 ; 0.5<$ $1 / n<1$, it is easy to adsorb; $1 / n>1$, it is difficult to adsorb (Samiey and Dargahi 2010). As shown in table 1, 


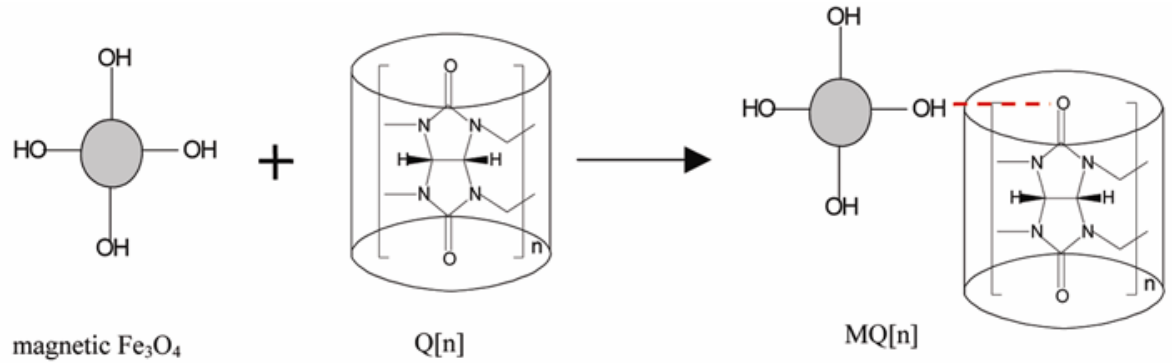

Figure 5. Schematic diagrams for the formation of $M Q[n]$.

Table 1. Values of Langmuir and Freundlich constants for the adsorption of HA.

\begin{tabular}{|c|c|c|c|c|c|c|c|}
\hline \multirow[b]{2}{*}{ Adsorbent } & \multirow[b]{2}{*}{$T(\mathrm{~K})$} & \multicolumn{3}{|c|}{ Langmuir isotherm } & \multicolumn{3}{|c|}{ Freundlich isotherm } \\
\hline & & $Q_{\mathrm{m}} /\left(\mathrm{mg} \mathrm{g}^{-1}\right)$ & $K_{\mathrm{L}}\left(\mathrm{L} \mathrm{mg}^{-1}\right)$ & $R^{2}$ & $K_{\mathrm{F}}\left(\mathrm{mg} \mathrm{g}^{-1}\right)$ & $1 / n$ & $R^{2}$ \\
\hline \multirow[t]{3}{*}{ HA } & 298 & $29 \cdot 38$ & 0.76 & $0 \cdot 918$ & 13.65 & $0 \cdot 80$ & 0.974 \\
\hline & 308 & $19 \cdot 10$ & 0.45 & 0.935 & $5 \cdot 53$ & 0.69 & 0.992 \\
\hline & 318 & 14.69 & $0 \cdot 36$ & 0.926 & $3 \cdot 60$ & 0.67 & $0 \cdot 961$ \\
\hline
\end{tabular}

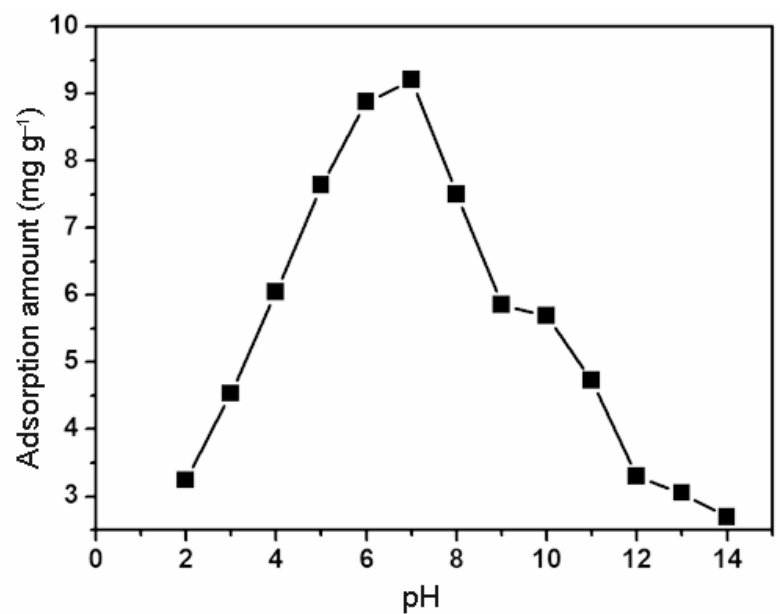

Figure 6. Effect of $\mathrm{pH}$ on the adsorption of HA onto MQ[n] at $298 \mathrm{~K}$.

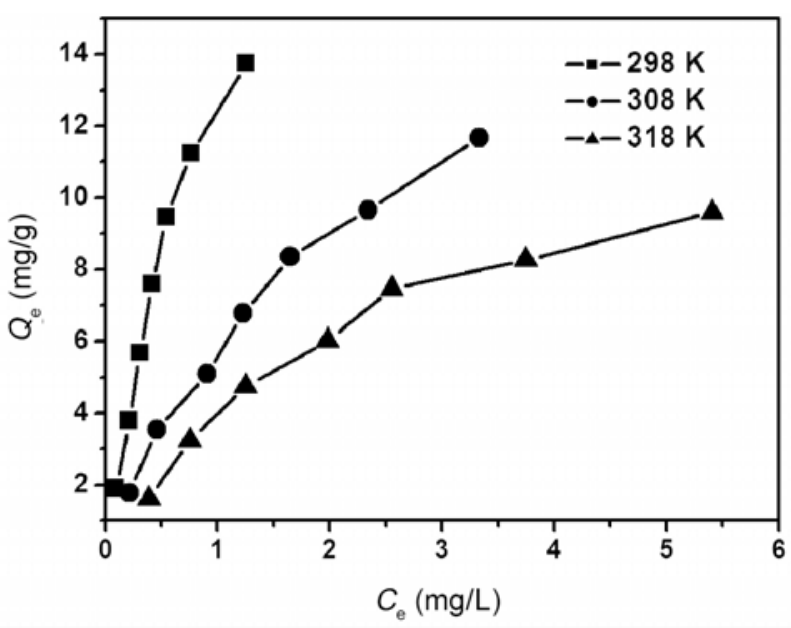

Figure 7. Adsorption isotherm of HA adsorption on $\mathrm{MQ}[n]$ at different temperatures. the $1 / n$ value of $\mathrm{HA}$ is between 0.6 and $0 \cdot 8$, indicating that HA can be easily adsorbed on the $\mathrm{MQ}[n]$. In addition, the $K_{\mathrm{F}}$ value is increased with temperature decrease, suggesting that decrease in temperature is in favour of the adsorption. Furthermore, Freundlich isotherm fits well and correlation coefficients are better. Thus, the adsorption process is suitable for Freundlich adsorption isothermal model, which indicates that HA adsorption on $\mathrm{MQ}[n]$ is multilayer adsorption with interaction between adsorbed molecules.

3.2c Thermodynamic parameters of adsorption: Adsorption thermodynamic parameters can provide deeper levels of information about energy transformation in adsorption process. Thermodynamic parameters of the adsorption process such as standard free energy $\left(\Delta G^{0}\right)$, standard enthalpy change $\left(\Delta H^{0}\right)$, and standard entropy change $\left(\Delta S^{0}\right)$ are calculated by the following equation (Tang et al 2012):

$$
\begin{aligned}
& \Delta G^{0}=-R T \ln K_{\mathrm{d}}, \\
& \ln K_{\mathrm{d}}=\Delta S^{0} / R-\Delta H^{0} / R T,
\end{aligned}
$$

where $R$ is the gas constant $\left(8.314 \mathrm{~J} \mathrm{~mol}^{-1} \mathrm{~K}^{-1}\right)$ and $T$ the absolute temperature. $K_{\mathrm{d}}$ is the equilibrium constant at temperature $T$. Standard free energy $\left(\Delta G^{0}\right)$ is calculated by (5). Plotting $\ln K_{\mathrm{d}}$ vs $1 / T, \Delta H^{0}$ and $\Delta S^{0}$ were obtained from the slope and intercept of van't Hoff plots (figure $8)$. The thermodynamic data were listed in table 2.

The negative values of $\Delta G^{0}$ at 288,298 and $308 \mathrm{~K}$ reveal that the adsorption process is spontaneous. With the increase in temperature, $\Delta G^{0}$ increases gradually and spontaneous tendency is weakened, inferring that the adsorption of HA on $\mathrm{MQ}[n]$ is difficult with increasing temperature. The negative value of $\Delta H^{0}$ explains exothermic nature of adsorption process and confirms that 
Table 2. Thermodynamic parameters of HA adsorption on the MQ[n].

\begin{tabular}{lcccc}
\hline Adsorbent & $T(\mathrm{~K})$ & $\Delta G^{\circ} /\left(\mathrm{kJ} \mathrm{mol}^{-1}\right)$ & $\Delta H^{\circ} /\left(\mathrm{kJ} \mathrm{mol}^{-1}\right)$ & $\Delta S^{\circ} /\left(\mathrm{J} \mathrm{mol}^{-1} \mathrm{~K}^{-1}\right)$ \\
\hline HA & 298 & -7.445 & & \\
& 308 & -4.439 & -65.772 & -197.766 \\
\hline
\end{tabular}

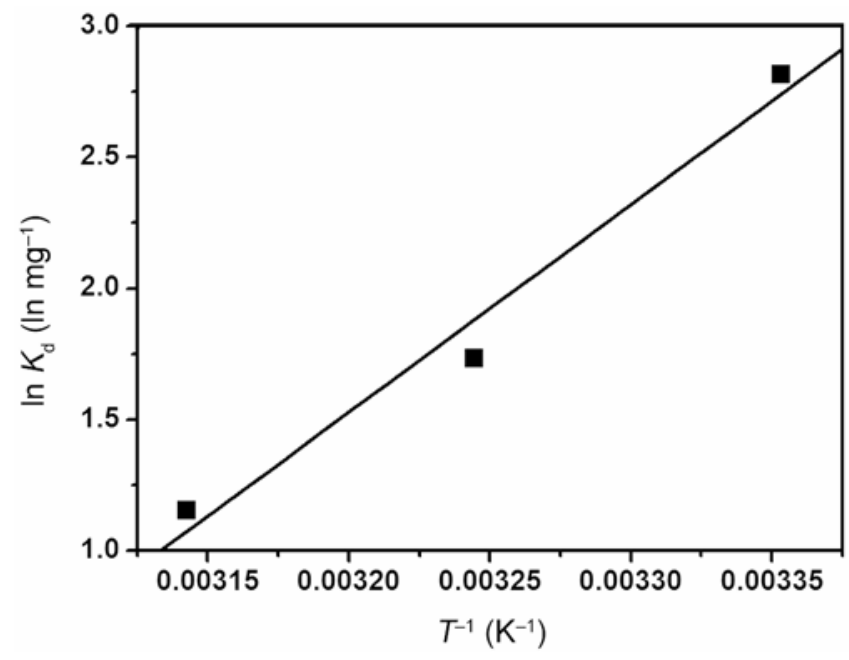

Figure 8. van't Hoff plots for the adsorption of HA on the $\mathrm{MQ}[n]$.

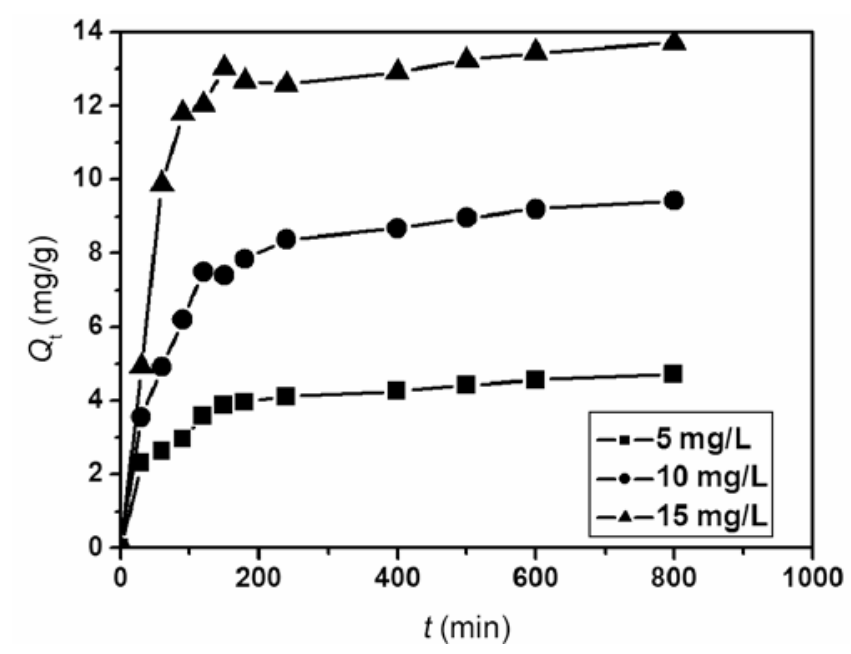

Figure 9. Adsorption kinetics of $\mathrm{HA}$ on $\mathrm{MQ}[n]$ at different initial concentrations.

the phenomenon of the adsorption capacity decreases as temperature increases. The negative value of $\Delta S^{0}$ suggests that the entropy reduction of the adsorption process and increased randomness at the solid-solution interface. Furthermore, the value of $\Delta H^{0}$ is $-65.772 \mathrm{~kJ} \mathrm{~mol}^{-1}$, which indicates that the adsorption process is a physico-chemical adsorption process rather than a pure physical or chemical adsorption process (Liang et al 2010). According to the structures of $\mathrm{MQ}[n]$ and HA, the force of adsorption process may be Van der Waals interaction, hydrophobic interaction and chemical bond force.

3.2d Adsorption kinetics: The adsorption kinetic curves of different initial concentration of HA adsorption onto $\mathrm{MQ}[n]$ are shown in figure 9. It is known that the three kinds of different initial concentrations of HA reach adsorption equilibrium in $12 \mathrm{~h}$. The adsorption kinetics of $\mathrm{HA}$ on $\mathrm{MQ}[n]$ was investigated with two kinetic models, which are pseudo-first-order and pseudo-second-order models (Lagergren et al 1898; Ho and McKay 1998). The pseudo-first-order model is expressed as

$$
\ln \left(Q_{\mathrm{e}}-Q_{\mathrm{t}}\right)=\ln Q_{\mathrm{e}}-K_{1} t
$$

where $Q_{\mathrm{e}}$ and $Q_{\mathrm{t}}$ are the amounts adsorbed at equilibrium time and time $t\left(\mathrm{mg} \mathrm{g}^{-1}\right) . K_{1}$ is the rate constant of the pseudo-first-order equation $\left(\mathrm{min}^{-1}\right)$. The results show that the experimented data are different from those calculated, which are obtained from the linear plots. The correlation coefficients $\left(R^{2}\right)$ are relatively low compared with these for pseudo-second-order model (table 3). So, the adsorption process is unsuitable for the pseudo-first-order model. The pseudo-second-order model is expressed as

$$
t / Q_{\mathrm{t}}=1 / K_{2} Q_{\mathrm{e}}{ }^{2}+t / Q_{\mathrm{e}},
$$

where $K_{2}$ is the rate constant of the pseudo-second-order equation $\left(\mathrm{g} \mathrm{mg}^{-1} \mathrm{~min}^{-1}\right)$. The values of $K_{2}$ are $5.31 \times 10^{-3}$, $2.40 \times 10^{-3}$ and $1.88 \times 10^{-3}$ at different initial concentrations of $\mathrm{HA}$, relating to the fast adsorption reaction ratio $\left(F=q_{\mathrm{t}} / q_{\mathrm{e}}\right)$ and the time of arrival in $F\left(t_{\mathrm{F}}\right)$. The correlation coefficients $\left(R^{2}\right)$ have high value $\left(R^{2}>0.99\right)$. In addition, the calculated maximum adsorption data are closer to the experimental data. Therefore, the pseudo-secondorder model can effectively fit the adsorption process. These facts suggest that adsorption mechanism is predominant for HA adsorption to $\mathrm{MQ}[n]$ and the ratelimiting step may be a chemisorption process.

3.2e Desorption experiments: Desorption study was carried out to investigate the feasibility to reuse the adsorbents. Because of the low adsorption of HA on $\mathrm{MQ}[n]$ and high solubility of $\mathrm{HA}$ at high $\mathrm{pH}, \mathrm{NaOH}$ was used to desorb the HA from MQ[n]. At the same time, in the basic solution, the positively charged nitrogen atoms were deprotonated and the electrostatic interaction 
Table 3. Fitting parameters of HA adsorption to MQ[n] using pseudo-first-order and pseudo-second-order kinetic models.

\begin{tabular}{|c|c|c|c|c|c|c|c|}
\hline \multirow[b]{2}{*}{$C_{0}\left(\mathrm{mg} \mathrm{g}^{-1}\right)$} & \multirow[b]{2}{*}{$q_{\exp }\left(\mathrm{mg} \mathrm{g}^{-1}\right)$} & \multicolumn{3}{|c|}{ First order kinetics } & \multicolumn{3}{|c|}{ Second order kinetics } \\
\hline & & $K_{1}\left(\min ^{-1}\right)$ & $q_{\mathrm{cal}}\left(\mathrm{mg} \mathrm{g}^{-1}\right)$ & $R^{2}$ & $K_{2}\left(\mathrm{~g} \mathrm{mg}^{-1} \mathrm{~min}^{-1}\right)$ & $q_{\text {cal }}\left(\mathrm{mg} \mathrm{g}^{-1}\right)$ & $R^{2}$ \\
\hline 5 & $4 \cdot 72$ & $4.67 \times 10^{-3}$ & $2 \cdot 54$ & 0.904 & $5.31 \times 10^{-3}$ & 4.85 & 0.996 \\
\hline 10 & $9 \cdot 42$ & $5 \cdot 21 \times 10^{-3}$ & $5 \cdot 05$ & 0.788 & $2.40 \times 10^{-3}$ & $9 \cdot 81$ & 0.996 \\
\hline 15 & $13 \cdot 71$ & $5.42 \times 10^{-3}$ & $5 \cdot 38$ & $0 \cdot 912$ & $1.88 \times 10^{-3}$ & $13 \cdot 99$ & 0.997 \\
\hline
\end{tabular}

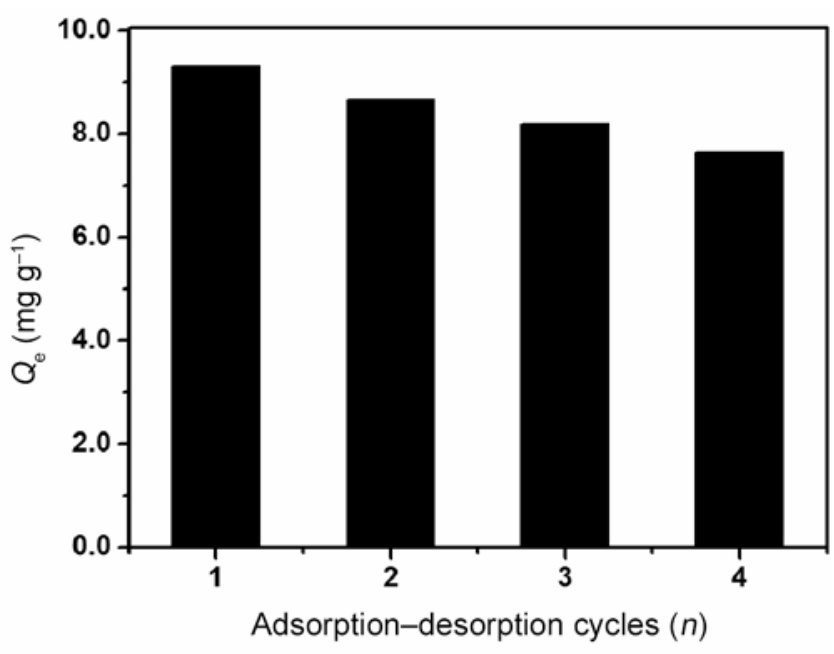

Figure 10. Adsorption amount of HA on regenerated MQ[n].

between $\mathrm{MQ}[n]$ and HA became much weaker. As shown in figure 10 , the adsorbent amount is gradually decreased with increasing number of cycles. The adsorbent amount decreased from 9.52 to $9.31 \mathrm{mg} \mathrm{g}^{-1}$ at first cycle. After four cycles, the adsorbent amount is down to $7.64 \mathrm{mg} \mathrm{g}^{-1}$, which is maintained up to $80 \%$ of first adsorbent amount, suggesting that $\mathrm{MQ}[n]$ has good adsorption capability and desorption property to be recycled for HA adsorption.

\section{Conclusions}

In this paper, $\mathrm{MQ}[n]$ was successfully synthesized with chemical co-precipitation method and the grafting of $\mathrm{Q}[n]$ molecules onto the $\mathrm{Fe}_{3} \mathrm{O}_{4}$ was confirmed by $\mathrm{FT}-\mathrm{IR}$, XRD and TGA. The adsorption studies showed that the adsorption capacity for HA depends on $\mathrm{pH}$ and adsorption process can be well represented by Freundlich adsorption isothermal model. The negative value of thermodynamic parameters suggested that the spontaneous and exothermic nature of adsorption process. The adsorption followed pseudo-second-order kinetics, which suggested that the limit factor of adsorption was adsorption mechanism and chemisorption process was a ratecontrolling step for adsorption. In addition, MQ[n] could be regenerated with alkaline wash. Therefore, it has great potential to be a novel and promising adsorbent for HA.

\section{Acknowledgements}

This work is supported by the National Natural Science Foundation of China (no. 21007050), Scientific Research Program Funded by Shaanxi Provincial Education Department, China (no. 12JK0455) and the Beilin District Foundation of Xi'an of China (no. GX1205).

\section{References}

Anirudhan T S, Suchithra P S and Rijith S 2008 Colloids Surf. 326147

Baker H and Khalili F 2004 Chim. Acta 516179

Bai R B and Zhang X 2001 J. Colloid Inter. Sci. 24352

Buschmann H -J, Jansen K and Schollmeyer E 2000 Thermochim. Acta 34633

Buschmann H -J, Mutihac L and Schollmeyer E 2006 J. Inclusion Phenom Mac. Chem. 56363

Buschmann H J and Schollmeyer E 1993 Textilveredelung 28 182

Bardelang D, Udachin K A and Leek D M 2007 Cryst. Eng. Commun. 9973

Bayramoglu G, Denizli A, Bektas S and Arica M 2002 Microchem. J. 7263

Domany Z, Galambos I, Vatai G and Bekassy-Molnar E 2002 Desalination 145333

Deng S and Bai R 2004 J. Colloid Inter. Sci. 28036

Feng X, Lu X J, Xue S F, Zhang Y Q, Tao Z and Zhu Q J 2009 Inorg. Chem. Commun. 12849

Ho Y and McKay G 1998 Chem. Eng. J. 70115

Ji Q, Liu H, Hu C, Qu J, Wang D and Li J 2008 Sep. Purif. Technol. 62464

Koparal A S, Yildiz Y S, Keskinler B and Demircioglu N 2008 Sep. Purif. Technol. 59175

Karcher S, Kornmüller A and Jekel Ma 2001a Water Res. 35 3309

Karcher S, Kornmüller A and Jekel M 2001b Water Res. 35 3317

Karcher S, Kornmüller A and Jekel M 1999 Water Sci. Technol. 40425

Latifoglu A and Gurol M D 2003 Water Res. 371879

Lim S, Kim H, Selvapalam N, Kim K J and Cho S 2008 Angew. Chem. Int. Ed. 473352

Langumuir I 1918 J. Am. Chem. Soc. 401361

Liang S, Guo X Y, Feng N C and Tian Q H 2010 J. Hazard. Mater. 174756

Lagergren S 1898 Handl 251

Peerannawar S R, Gobre V V and Gejji S P 2012 Comput. Theor. Chem. 98316 
Petrov N K, Ivanov D A, Golubkov D V, Gromov S P and Alfimov M V 2009 Chem. Phys. Lett. 480, 96

Parsonage P 1992 Colloid Chem. Miner. Process. 11331

Senem U C, Suphandaga S A, Kercb A and Bekboleta M 2007 Desalination 210183

Seredýnska-Sobecka B, Tomaszewska M and Morawski A W 2006 Desalination 198265

Saleh N, Al-Soud Y A, Al-Kaabi L, Ghosh I and Nau W M 2011 Tetrahedron Lett. 525249

Samiey B and Toosi A 2010 J. Hazard. Mater. 184739

Samiey B and Dargahi M 2010 Cent. Europ. J. Chem. 8906

Tang C Y, Kwon Y N and Leckie J O 2007 J. Membr. Sci. 29086

Tang H, Zhou W J and Zhang L N 2012 J. Hazard. Mater. 209210218
Vreysen S and Maes A 2008 Appl. Clay Sci. 38237

Wang S B and Zhu Z H 2007 J. Coll. Interf. Sci. 31541

Wang J N, Zhou Y, Li A M and Xu L 2010 J. Hazard. Mater. 1761018

Wei F, Min S, Xu L, Cheng G Z, Wu C T and Feng, Y Q 2005 Electrophoresis 262214

Wheate N J 2008 J. Inorg. Biochem. 1022060

Yang Q, Yang Y L, Wang W D, Ge M and Li D 2012 Adv. Mater. Res. 413217

Zhao L, Luo F, Wasikiewicz J M, Mitomo H, Nagasawa N, Yagi T, Tamada M and Yoshii F 2008 Bioresour. Technol. 99 1911

Zhang Y Q, Zhen L M, Yu D H, Zhao Y J, Xue S F, Zhu Q J and Tao Z 2008 J. Mol. Struct. 875435 